Article

Subscriber access provided by King Abdullah University of Science and Technology Library

\title{
Buried Volume Analysis for Propene Polymerization Catalysis Promoted by Group 4 Metals: a Tool for Molecular Mass Prediction
}

Laura Falivene, Luigi Cavallo, and Giovanni Talarico

ACS Catal., Just Accepted Manuscript • DOI: 10.1021/acscatal.5b01363 • Publication Date (Web): 02 Oct 2015

Downloaded from http://pubs.acs.org on October 6, 2015

\section{Just Accepted}

"Just Accepted" manuscripts have been peer-reviewed and accepted for publication. They are posted online prior to technical editing, formatting for publication and author proofing. The American Chemical Society provides "Just Accepted" as a free service to the research community to expedite the dissemination of scientific material as soon as possible after acceptance. "Just Accepted" manuscripts appear in full in PDF format accompanied by an HTML abstract. "Just Accepted" manuscripts have been fully peer reviewed, but should not be considered the official version of record. They are accessible to all readers and citable by the Digital Object Identifier (DOI®). "Just Accepted" is an optional service offered to authors. Therefore, the "Just Accepted" Web site may not include all articles that will be published in the journal. After a manuscript is technically edited and formatted, it will be removed from the "Just Accepted" Web site and published as an ASAP article. Note that technical editing may introduce minor changes to the manuscript text and/or graphics which could affect content, and all legal disclaimers and ethical guidelines that apply to the journal pertain. ACS cannot be held responsible for errors or consequences arising from the use of information contained in these "Just Accepted" manuscripts. 
Propene polymerization promoted by Group 4 homogeneous single site catalysts is an extraordinary meeting point of experiments and computational modeling. ${ }^{1}$ As a matter of fact, due to the impressive experimental work performed since $1984,{ }^{2-3}$ computational tools (normally routed into the Density Functional Theory, DFT) have been frequently used to explain expected or rationalize unexpected results ex post. ${ }^{4-6}$ The stereoregulation as well as the regioregulation mechanisms have been rationalized on the basis of precursor symmetries (usually neutral dichloride or dimethyl complexes) and the microstructure of the resulting polypropylenes ${ }^{7,8}$ can be predicted, with few exceptions. The well-accepted mechanism of stereocontrol based on the "growing chain orientation" allows to predict stereoselectivity in good agreement with experiments, at least for metallocene and post-metallocene systems. ${ }^{9}$ Similarly, the enantioselectivity of a 2,1 insertion has been related to the local symmetry of the ligand. ${ }^{10}$ Together with the elements influencing the enantioselectivity of propene, insertion, it is clear that controlling and predicting the molecular mass of the resulting polymers is desirable. However, no clear quantitative statistical correlation between the structure of the precatalyst and the polypropylene molecular mass has been reported so far. The main reason for this gap is the difficulty in computing the degree of polymerization (here defined as the average degree of polymerization, $\bar{P}_{n}$ ) which in turn it is translated into the calculation of propagation/termination rates, see Eq. 1,

$$
\text { Eq. } 1 \quad \bar{P}_{n}=\frac{R_{P}}{\sum R_{T}}
$$

where $R_{P}$ is the overall rate of propagation and $R_{\mathrm{T}}$ are the rates of all chain termination reactions. The two main chain termination mechanisms promoted by Group 4 catalysts are: (i) bimolecular $\beta$-hydrogen transfer (BHT) from the growing chain to the monomer and (ii) unimolecular $\beta$-hydrogen elimination (BHE) from the growing chain to the metal.

As far as concern the BHT, ${ }^{4}$ it is an associative mechanism passing through a transition state (TS) that resembles a metal hydride-bis(olefin) complex ${ }^{5,11 a}$ and a more general definition of this pathway has recently been proposed including a metalmediated $\mathrm{H}$ transfer $\left(\mathrm{BHT}_{\mathrm{A}}\right)$, a direct transfer $\left(\mathrm{BHT}_{\mathrm{B}}\right)$, and a two-steps associative displacement $\left(\mathrm{BHT}_{\mathrm{C}}\right)$. $^{1 \mathrm{~b}}$

The BHE is essentially dissociative; being of zero-order with respect to the monomer if this were the dominant chain release mechanism, the polypropylene molecular mass would be dependent on the monomer concentration. Unfortunately, putting BHE on the same free-energy scale as the insertion and BHT paths is complicate because these reactions differ in molecularity, which creates problems when calculating freeenergy differences in solvent. Furthermore, the $\beta$-hydrogen transfer to the metal TS could be not representative of the real energy barrier needed for this chain release process, unless associative displacement of the olefin-like chain end by a monomer or a solvent molecule takes place. Scheme S1 reported in Supporting Information summarizes the above concepts. These factors explain why, to the best of our knowledge, only one attempt to put calculated BHE energies on the same free-energy scale as propagation and BHT by using empirical corrections has been reported. ${ }^{11 \mathrm{~b}}$ Apart from BHT and BHE, other mechanisms like $\beta$-methyl elimination or transfer to the co-catalyst have been recognized as important. The former pathway occurs for metallocenes bearing very bulky ligands, such as $\mathrm{Cp}^{*}{ }^{12}$ the latter one might be predomi- 
nant in case of drastic experimental conditions (e.g. very low monomer concentrations and high co-catalyst/catalyst ratio). ${ }^{13}$ In summary, the chain-release step involves not only a variety of mechanistic pathways but also a surprisingly fluidity depending on subtle changes in the metal and in the ligands. Nevertheless, despite this complexity it has been demonstrated that the dominant termination mechanism with the large majority of Group 4 metallocenes and post-metallocenes, under practical experimental conditions is the BHT. ${ }^{4 a, 13}$

In combination with the catalyst structure, also the experimental parameters (temperature, monomer concentration, nature of co-catalyst, co-catalyst/catalyst ratio, solvent) influence the molecular mass. Finally, it is worth to recall that for propene polymerization the degree of polymerization is also dependent on the regiochemistry, since chain transfer is much more likely to take place after a secondary insertion, making termination favorable over chain propagation. ${ }^{14}$

By reviewing the literature, we summarize few guidelines related to the bulkiness of the active pocket that influence the ratio between insertion and termination rates:

A) A more open coordination sphere explains the higher molecular masses achieved with group 4 constrained geometry catalysts (CGCs, systems $\mathbf{1}$ and $\mathbf{2}$ in Chart 1), ${ }^{15-18}$ with respect to ansa-metallocenes (e.g. systems 3-12). Interestingly, industrial applications were found only for Ti-based systems since the $\mathrm{Zr}$-homologues are unable to produce polymers with acceptable molecular mass. Furthermore, the importance of a "proper" coordination sphere around the metal (namely the angle $C \mathrm{p}_{\text {centroid }}-\mathrm{M}-\mathrm{C} \mathrm{p}_{\text {centroid }}$ in metallocenes) accounts also for the effects of the bridge in the ansa-metallocenes (e.g. $\mathrm{Si}\left(\mathrm{CH}_{3}\right)_{2}$ in place of $-\mathrm{C}\left(\mathrm{CH}_{3}\right)_{2}$, see systems $\mathbf{3}$ and $\mathbf{4}$, or $\mathrm{Si}\left(\mathrm{CH}_{3}\right)_{2}$ instead of $-\mathrm{Si}(\mathrm{Ph})_{2}$, see systems 6 and 7). ${ }^{19}$

B) Suitable modification of the metallocene skeleton, as the methyl substitution on the 2,2' position on the indenyl or benzindenyl ligand, ${ }^{20,21}$ can suppress the $\beta$-hydrogen transfer to the monomer increasing the average molecular mass (compare systems $\mathbf{4}, \mathbf{8}$ and $\mathbf{1 0}$ with $\mathbf{5 , 9}$ and 11, respectively).

C) Changing the metal maintaining the same ligand scaffold allows to reach higher molecular mass (e.g. Hf complexes yield polymers with higher average molecular masses than the Zr homologues. ${ }^{20,22}$ )

D) Modification of ligand framework by using postmetallocene catalysts ${ }^{23}$ enlarges the range of olefin-based materials accessible. Typical example are the $\mathrm{C}_{2}$-aminophenolate octahedral complexes ${ }^{23}$ presenting ortho-phenolate substituents (see systems 17-18 of Chart 1). ${ }^{24}$

E) Enhancing the stability of the polymer chain by weak interactions with the ligand makes the $\beta-\mathrm{H}$ atom of the growing chain less prone to be transferred to the metal and/or to the monomer. These interactions explain the non-living character of octahedral bis(phenoxy-imine) catalysts (see systems 22-23 of Chart 1) with respect to the "living" polymerization behavior shown by the analogous ortho-fluoro systems (see systems 25-26 of Chart 1). ${ }^{25}$

In principle both steric and electronic properties contribute to behavior described in points A-E above; in practice it is well accepted that steric effects play the predominant role. ${ }^{4 a, 5,6}$

In this work we have revised the above concepts aiming to characterize and quantify the proper coordination sphere around the metal, and the suitable ligand framework to obtain higher molecular mass polymers, possibly linking the metal role with ligand effects. We have focused on the neutral precursor features, since this approach allows to define a "training set" property that could be applied in fast methods like the quantitative structure-activity relationship technique (QSAR) widely used in medicinal chemistry for the design of new and more efficient drugs.

With this aim in mind, we decided to measure the steric hindrance of a series of Group 4 propylene polymerization catalysts using the buried volume $\left(\% V_{\text {Bur }}\right)$ descriptor. The buried volume gives a measure of the space occupied by the ligand in the first coordination sphere of the metal (see Figure 1). Initially developed to characterize the steric properties of $\mathrm{N}$ heterocyclic carbenes (NHC), ${ }^{26}$ the $\% V_{\text {Bur }}$ descriptor has been successfully used also to rationalize the behavior of catalysts bearing ligands different from NHCs. ${ }^{27}$

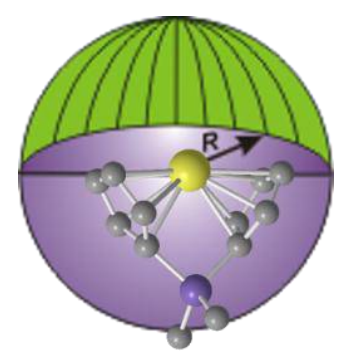

Figure 1. Graphical representation of the sphere used to calculate $\% V_{\text {Bur }}$ values for the catalytic precursors of Chart 1.

In the following the $\% V_{\text {Bur }}$ will be used to correlate the steric hindrance of the neutral precursors shown in Chart 1 to the energy difference between the propagation TS (INS) and the lower monomer chain transfer TS (corresponding to the metalmediated $\mathrm{H}$ transfer $\left(\mathrm{BHT}_{\mathrm{A}}\right)$, or the direct transfer $\left(\mathrm{BHT}_{\mathrm{B}}\right){ }^{11 \mathrm{~b}}$ computed by DFT calculations.

\section{Methods}

All the DFT static calculations have been performed at the HGGA level with the Gaussian09 set of programs, ${ }^{28}$ using the B3LYP functional. ${ }^{29}$ The electronic configuration has been described with the standard split-valence basis set with a polarization function of Ahlrichs and co-workers for $\mathrm{H}, \mathrm{C}, \mathrm{N}$, and $\mathrm{O}(\mathrm{SVP})^{30}$ and with the SDD basis and pseudopotential ${ }^{31}$ at the metal (a f function with exponent 0.5 was added for $\mathrm{Hf}$ ). Stationary points were characterized using vibrational analysis, and this analysis has been also used to calculate zero-point energies and thermal (enthalpy and entropy) corrections (298.15 K, 1 bar). Improved electronic energies were obtained from single-point energy calculations using a TZVP basis set ${ }^{32}$ on the main atoms; these energies added to the SVP-level thermal corrections are named $\Delta G(\mathrm{~B} 3 / \mathrm{TZVP})$. For a comparison with experimental data we computed the free energies including solvent effects (toluene) with the PCM model, ${ }^{33}$ and dispersion corrections ${ }^{34}$ (EmpiricalDispersion=D3 in the Gaussian09 D.01 package), named $\Delta G$ (B3/D3/TZVP/PCM). 
In Supporting Information we report both these energies in order to estimate the influence of both dispersion correction and solvent effect. In the remainder of the paper for clarity we are using the term $\Delta G_{\mathrm{DFT}}$ as synonymous of $\Delta G$ (B3/D3/TZVP/PCM) when computing the free energy differences between the lower insertion TS and the lower BHT $\left(\mathrm{BHT}_{\mathrm{A}}\right.$ or $\left.\mathrm{BHT}_{\mathrm{B}}\right)$. However, when comparing our results with the experimental data including $\mathrm{BHE}$ values calculated by empirical approach we will use the term $\Delta G_{\text {calc }}$.

The growing polymer chain was simulated by an iso-butyl group, and only the most stable TSs are reported. Although systems 23 and 26 promote propene polymerization by secondary insertion, we used a primary chain to have a fair comparison between different ligands. Moreover, the effect of a secondary propagation was already reported for systems $\mathbf{2 3}$ (see ref. 14), whereas experimentally a living propagation has been found for system $\mathbf{2 6}$. $^{25}$

The $\% V_{\text {Bur }}$ reported in the paper have been computed using the SambVca package developed by some of us. ${ }^{35}$ The program analyzes the first coordination sphere around the metal, which is the place where catalysis occurs.

The optimized geometry of the $\mathrm{L}-\mathrm{M}-\mathrm{Cl}_{2}$ complexes under analysis has been properly oriented. After this alignment step the metal and the $\mathrm{Cl}$ ligands have been removed, and the first coordination sphere around the metal is analyzed. This sphere, of radius $R$, is sectioned by a regular 3D cubic mesh of spacing $s$, which defines cubic voxels, $v$. The distance between the center of each voxel with all the atoms in the ligand is tested to check if any of the atoms is within a van der Waals distance from the center of the examined voxel. If no atom is within a van der Waals distance, the examined voxel is marked as a free voxel. Otherwise, the examined voxel is marked as buried.

With this description, Eq. 2 holds:

Eq. $2 V_{\text {Sphere }}=\Sigma \mathrm{v}_{\mathrm{xyz}}=V_{\text {free }}+V_{\text {Bur }}=\Sigma \mathrm{v}_{\mathrm{xyz}}($ Free $)+\Sigma \mathrm{v}_{\mathrm{xyz}}($ Buried $)$

While the $V_{\text {Bur }}$ already indicates the amount of the coordination sphere that is occupied by the considered ligand, we prefer the more intuitive $\% V_{\text {Bur }}$ descriptor of Eq. 3, which simply is:

Eq. $3 \% V_{\text {Bur }}=100 * V_{\text {Bur }} / V_{\text {Sphere }}$

A modified version of Samb $V$ ca allows the user to perform a more detailed analysis by evaluating the $\% V_{\text {Bur }}$ in the single quadrants around the metal center. Splitting the total $\% V_{\text {Bur }}$ into quadrant contributions quantifies any asymmetry in the way the ligand wraps around the metal and allows to understand the change in the shape of the reactive pocket. The advanced version of the program gives the possibility to calculate also the steric map of the ligand. ${ }^{36}$

To build the steric map, after all the voxels in the first coordination sphere have been marked as free or buried, for each $(\mathrm{x}, \mathrm{y})$ point within the first coordination sphere, the program scans the sphere from the top (i.e. away from the ligand) to find at which $\mathrm{z}$ value there is the first buried voxel.

This procedure results in a surface, defined as $S(\mathrm{x}, \mathrm{y})=\mathrm{z}_{\mathrm{B}}$, which represents the surface of the ligand that is exposed towards the incoming reactants. In other words, this $S(\mathrm{x}, \mathrm{y})=\mathrm{z}_{\mathrm{B}}$ surface defines the shape of the reactive pocket.

Finally, the maps are a simple $2 \mathrm{D}$ isocontour representation of the interaction surface $S(\mathrm{x}, \mathrm{y})=\mathrm{z}_{\mathrm{B}}$. In this work, the radius $R$ of the sphere around the metal center was set to $3.5 \AA$, while for the atoms we adopted the Bondi radii $^{37}$ scaled by 1.17 , and a mesh of $0.1 \AA$ was used to scan the sphere.

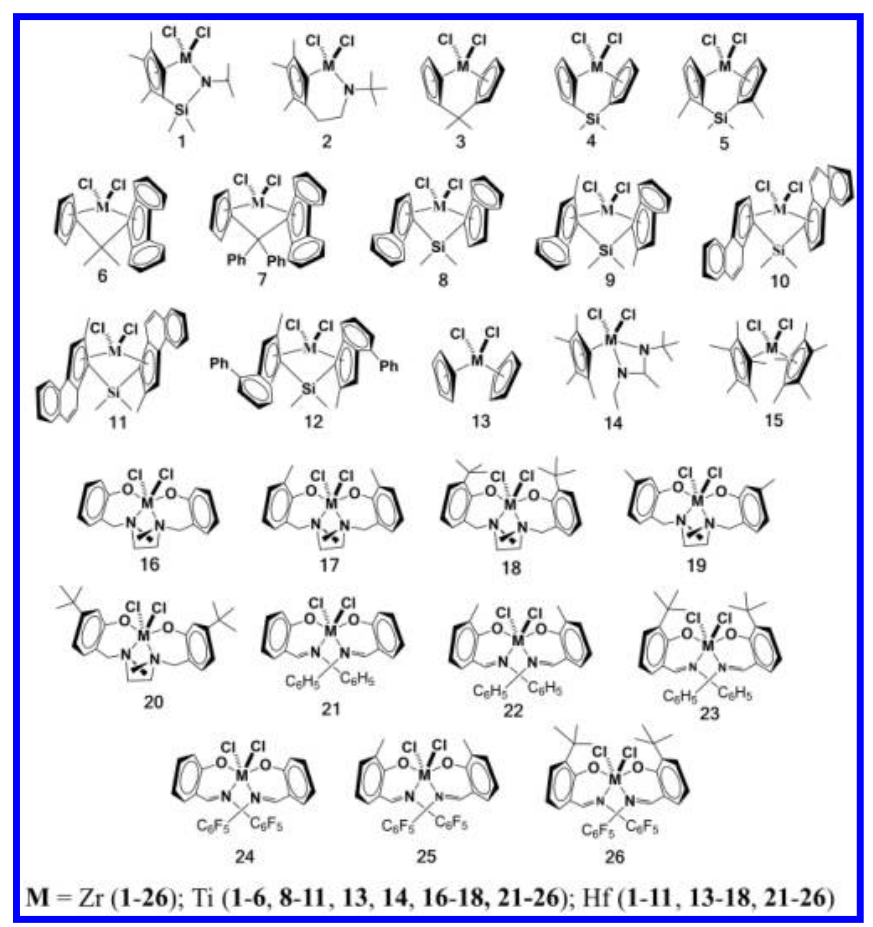

Chart 1. Systems analyzed in the present study.

\section{Results and Discussions}

The catalytic systems investigated in this study are reported in Chart 1. They have been selected to match the general statements A-E defined in the Introduction. Together with the $\mathrm{C}_{2 \mathrm{v}^{-}}$ aspecific (systems 3, 4, 13 and 15) and $\mathrm{C}_{2}$-isospecific (systems 5, 8-12) metallocenes, we also included the $\mathrm{C}_{\mathrm{S}}$-syndiospecific systems $^{38} \mathbf{6}$ and $\mathbf{7}$ to complete the relationship symmetry/microstructure, and the $\mathrm{C}_{1}$-symmetric system $\mathbf{1 4}$, which produces prevailingly isotactic polypropylene. ${ }^{39}$ The $\mathrm{C}_{2^{-}}$ symmetric octahedral systems 16, 19 and 20 were included to check the effect of substituents in the ortho, meta and para positions of the salan ligand. ${ }^{23}$ Systems 21 and $\mathbf{2 4}$ were studied to check the effect of substituents in the ortho position ${ }^{40}$ as well as the ortho-fluoro effect on bis(phenoxy-imine), systems 23 and 26, respectively. ${ }^{25,41}$ Finally, we included also the very bulky metallocene $\mathbf{1 5}$, despite it is known to promote polypropylene of low molecular mass through $\beta$-methyl elimination. ${ }^{12}$

In the next section we briefly discuss the comparison between the bulkiness of the neutral precursor and that of DFT calculated TSs for INS and $\mathrm{BHT}_{\mathrm{A}}$ for prototype metallocene and post-metallocene systems (4 and $\mathbf{1 6}$ of Chart 1).

In Figure 2 we report the steric maps calculated for the dichloride precursor and the TSs for insertion and BHT in the prototype metallocene 4 (2a) and octahedral non-metallocene 16 (2b). These maps clearly show a strong similarity between the catalytic pocket in the neutral precursor and in the two competing TSs. This indicates limited flexibility in the catalysts scaffold that translates in a high rigidity of catalytic pocket. 
This result allows limiting the steric analysis to the neutral precursors, which is the approach followed in the remaining of this paper. Focusing on a comparison between the maps of $\mathbf{4}$ and 16, it emerges clear that the octahedral system $\mathbf{1 6}$ has much less hindrance in the east and west hemispheres, which is consistent with the higher flexibility in the regiochemistry of propene insertion exhibited by octahedral group 4 catalysts bearing phenoxy-amine or phenoxy-imine ligands. ${ }^{42}$

a)

Top
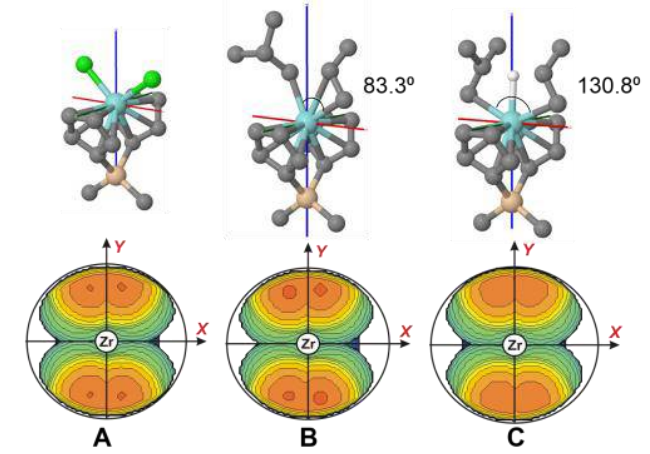

b)

Top

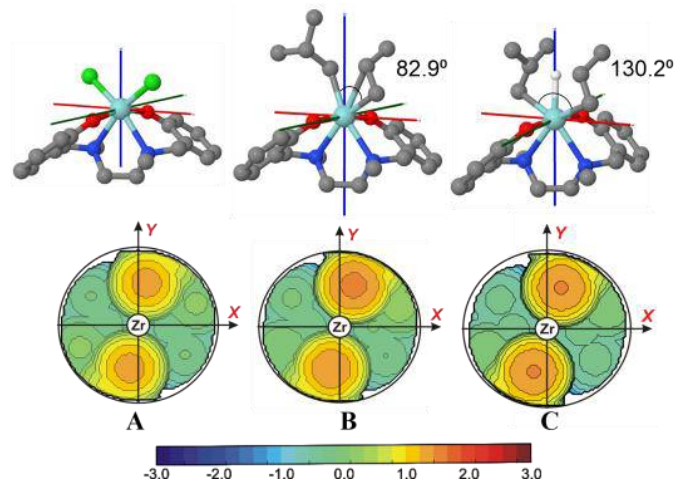

Figure 2. a) Steric maps for system 4 at the bottom. The metallocenes are oriented placing the metal center at the origin of the sphere, with the $\mathrm{M}-\mathrm{Si}$ axis aligned along the $\mathrm{z}$ axis at negative $\mathrm{z}$ values and with one Me group in the xz plane as indicated at the Top; b) Steric maps for system $\mathbf{1 6}$ at the bottom. The systems are oriented placing the metal center at the origin of the sphere, with the middle point if the $\mathrm{N}$ atoms aligned along the $\mathrm{z}$ axis at negative $\mathrm{z}$ values and with one $\mathrm{N}$ atom in the $\mathrm{xz}$ plane as indicated at the Top. A, $\mathbf{B}, \mathbf{C}$ are the maps of the neutral dichloride precursor, the cationic propagating TS and the $\mathrm{BHT}_{\mathrm{A}} \mathrm{TS}$, respectively.

Our analysis continues with the classical silyl-bridged CGC system 1. As stated in literature CGC systems are characterized by a more open coordination sphere that allows an easier incorporation of bulkier monomers (e.g. 1-hexene or 1octene). ${ }^{18}$ To verify this hypothesis, the steric maps and the $\% V_{\text {Bur }}$ divided into quadrants ${ }^{35}$ for the dichloride precursors of 1 with $\mathrm{Ti}$ and $\mathrm{Zr}$ are reported in Figure 3. Comparing Figure 2a-A with Figure $3 \mathrm{~A}$ indicates that replacing one of the $\mathrm{Cp}$ ligands of metallocenes with the amido $\mathrm{N}$-tert-butyl ligand decreases the bulkiness around the metal center, whereas replacing $\mathrm{Cp}$ with $\mathrm{Cp} *$ does the opposite. Focusing on the metal effect, the Ti structures are more crowded than the corresponding $\mathrm{Zr}$ ones (compare the $\% V_{\text {Bur }}$ in the quadrants, i.e. $80.1 \mathrm{vs}$. 74.8 etc). Smaller effects can be envisaged by changing the substituent on the $\mathrm{N}$ atom (here a tert-butyl group). These results are in agreement with the experimental findings, since the Ti-based catalysts are used for the industrial production of

high mass EPR copolymers, with the molecular mass depending on the bulkiness of the amido N-substituent. ${ }^{18 c}$

Top

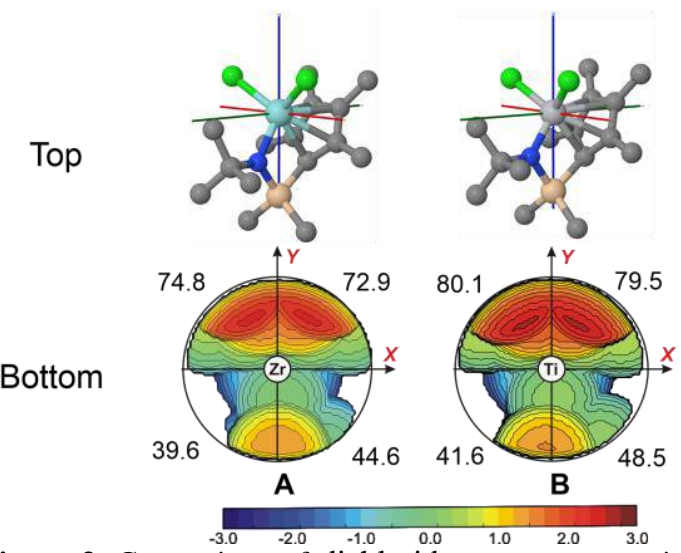

Figure 3. Comparison of dichloride precursors steric maps for the system $1 \mathrm{Zr}(\mathrm{A})$ and $\mathrm{Ti}(\mathrm{B})$. The CGC are oriented placing the metal center at the origin of the sphere, and with the M-Si axis aligned along the $\mathrm{z}$ axis at negative $\mathrm{z}$ values and with one $\mathrm{Me}$ group in the xz plane as indicated at the Top in the DFT calculated structures.

Moving to smaller structural effects, the role of substituents on a predefined ligand scaffold, related to the so called rational catalyst design, point $\mathrm{B}$ in the Introduction, can be also easily rationalized by steric maps. In Figure 4A the "difference" map between the precursors of systems $\mathbf{1 1}$ and $\mathbf{1 0}$ shows the effect of the $2,2^{\prime}$ methyl substitution on the benzindenyl skeleton. ${ }^{21}$ The increased hindrance in system $\mathbf{1 1}$ is properly placed to disfavor the more space demanding $\mathrm{BHT}_{\mathrm{A}} \mathrm{TS}$ through repulsive interaction within the metallocene equatorial belt. ${ }^{11 a}$ Similar results are obtained by analysis of the difference map between systems $\mathbf{9}$ and $\mathbf{8}$.

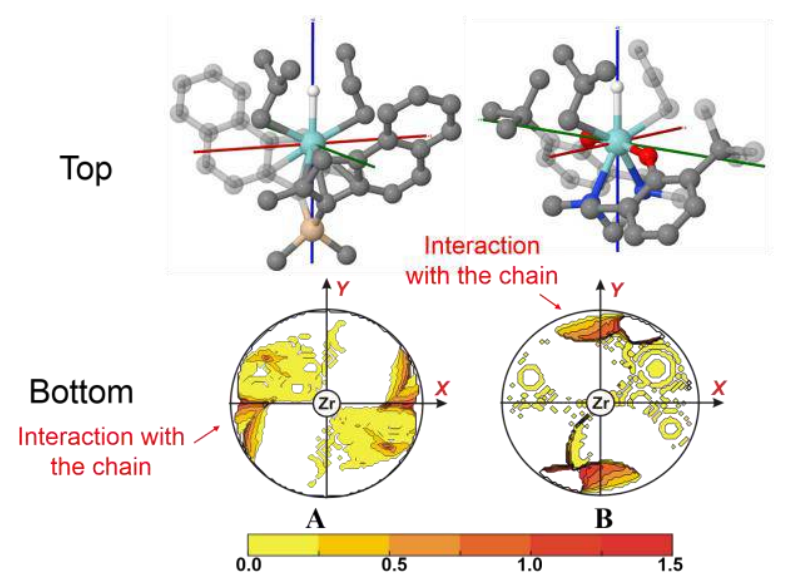

Figure 4. Steric maps reporting the steric difference between metallocene systems 10 and 11 (A) and post-metallocene 16 and 18 (B) for $\mathrm{BHT}_{\mathrm{A}}$ at Bottom. At the Top the DFT optimized structures oriented as in the maps are reported.

As for the octahedral complexes 16-18, we previously reported that the bulkiness of the ortho-phenolate substituents on the octahedral framework might play a role similar to the 2,2'methyl substitution on the metallocene skeleton. ${ }^{43}$ The "difference" map of Figure 4B, between systems $\mathbf{1 8}$ and $\mathbf{1 6}$ shows that the tert-butyl groups in $\mathbf{1 8}$ have a dual role. They 
generate the needed asymmetry in the chiral pocket to induce stereoselective propene insertion and prevent the BHT reaction by creating steric hindrance that destabilizes the BHT TS, see Figure $2 b-C$. In summary, the buried volume and the steric map descriptors allowed to unify ideas spread in the literature on the molecular mass capability of basically all group 4 polymerization catalysts, independently of the specific coordination geometry and ligand scaffold.

After revisiting of known concepts, we move to a quantitative level of analysis by plotting the calculated buried volume of the neutral precursors versus the energy difference between the termination and propagation TSs, $\Delta G_{\mathrm{DFT}}$, which should be directly correlated to the molecular mass capability of a given catalyst. Considering that the different metals have different electronic propensity toward insertion and termination, we separated the systems according to the metal. It is worth to remember that the correlation is depending on the DFT level used (e.g. functional, basis set, solvent model and dispersion correction) and it is well known that the hydrogen transfer represents a "classic" DFT problem. ${ }^{44}$ In Figure 5 we report the set of data for zirconium system (corresponding to $\Delta G$ (B3/TZVP/PCM/D3, here, $\Delta G_{\mathrm{DFT}}$ ), see Methods section), whereas the $\Delta E(\mathrm{~B} 3 / \mathrm{TZVP} / \mathrm{PCM} / \mathrm{D} 3$ as well as $\Delta E$ and $\Delta G$ (B3/TZVP) are reported in Table $\mathrm{S} 1$.

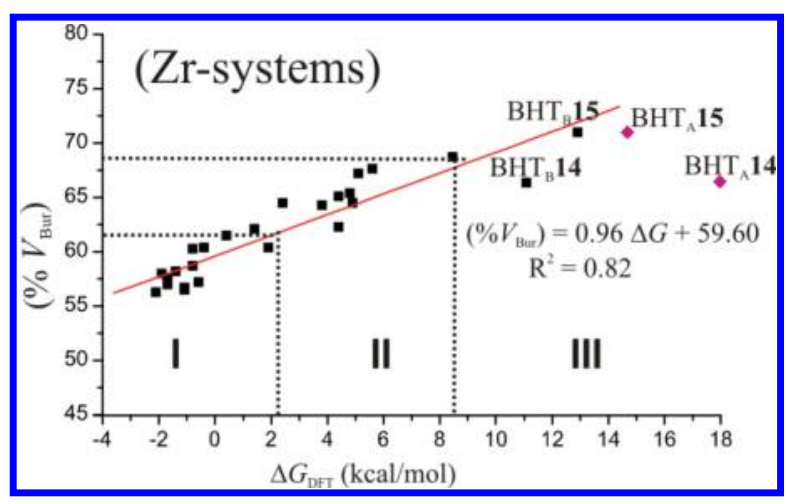

Figure 5. Plot of $\Delta G_{\mathrm{DFT}}$ versus ( $\% V_{\mathrm{Bur}}$ ) for the $\mathrm{Zr}$ systems of Chart 1 . With the dashed line are indicated the three classes (I, II, III) discussed in the text.

Results indicate a good correlation between the $\% V_{\mathrm{Bur}}$ of the neutral precursors and the $\Delta G_{\mathrm{DFT}}$, with $\mathrm{R}^{2}$ square 0.82 , considering that the $\% V_{\mathrm{Bur}}$ only accounts for steric effects. ${ }^{45}$

Moreover, the plot of Figure 5 suggests that the $\mathrm{Zr}$ systems can be collected in three classes as reported by dashed lines in Figure 5: class I, systems with the $\% V_{\text {Bur }}<62$; class II, systems with the $\% V_{\mathrm{Bur}}$ in the range 62-68; class III, systems with $\% V_{\text {Bur }}>68$ (the complete list is reported in Table S1). Systems belonging to the first class (I) are characterized by a low $\Delta G_{\mathrm{DFT}}$ value (i.e. they promote polypropylene with low molecular mass). ${ }^{46}$ This is the case e.g. of CGC, metallocene without "proper" modification and octahedral systems (see Table S1). Interestingly, both the ortho-phenolate substitution and the ortho-fluoro effect seem not to be as effective on $\mathrm{Zr}$ post-metallocene as the simple 2,2' methyl substitution on zirconocene skeleton. ${ }^{20,21}$ Within class II there are systems yield to higher molecular mass polymers like ansametallocene with "suitable" modifications and proper ligand framework. Finally, class III systems, despite reporting a very high $\Delta G_{\mathrm{DFT}}$, have highly hindered catalytic pockets that exper- imentally show alternative chain transfers (BHE or $\beta$-methyl elimination, as in the system 15). This nicely correlates with the evidence that, for such systems, the direct transfer $\mathrm{BHT}_{\mathrm{B}}$ becomes lower in energy than $\mathrm{BHT}_{\mathrm{A}}$. For a better visualization we reported in Figure 5 both $\mathrm{BHT}_{\mathrm{A}}$ and $\mathrm{BHT}_{\mathrm{B}}$ values for systems 14 and 15, in the fit we considered the two $\mathrm{BHT}_{B}$ values. A comparison of $\mathrm{BHT}_{\mathrm{A}}$ and $\mathrm{BHT}_{\mathrm{B}}$ for system 14 is reported in Figure S1, of Supporting Information. ${ }^{6,11}$

As last remark, it seems that the fine tuning of ansazirconocene systems has reached the highest level (see system $\mathbf{1 2}$ at the border line of class II and III) to obtain high molecular mass and that there is no enough space to further improvements within the ansa-metallocene framework. ${ }^{47}$ The plots of $\Delta G(\mathrm{~B} 3 / \mathrm{TZVP} / \mathrm{PCM} / \mathrm{D} 3)$, here $\Delta G_{\mathrm{DFT}}$, versus $\% V_{\mathrm{Bur}}$ values for $\mathrm{Ti}$ and Hf systems of Chart 1 are reported in Figure $6 \mathbf{A}$ and $\mathbf{B}$, respectively and Table $\mathrm{S} 2$.

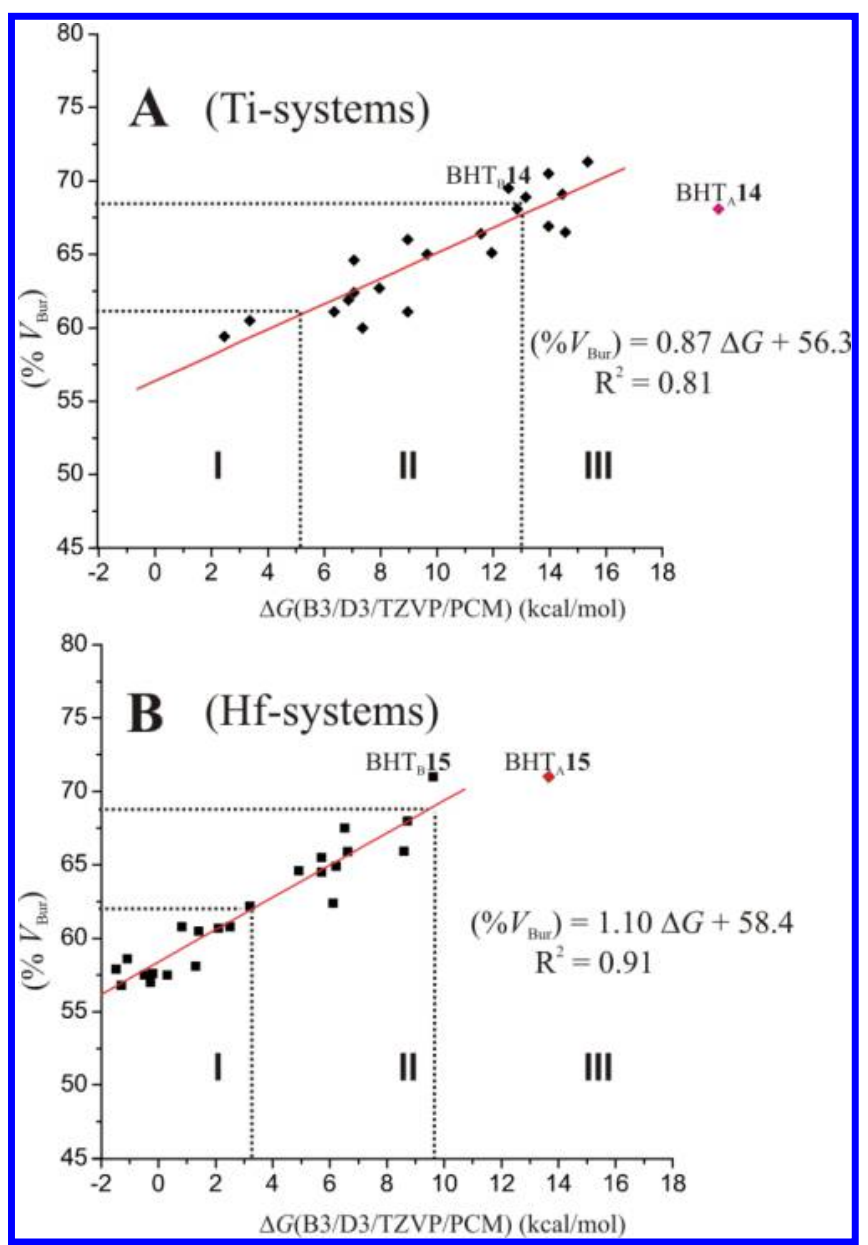

Figure 6. Plot of the $\Delta G_{\mathrm{DFT}}$ versus $\left(\% V_{\mathrm{Bur}}\right)$ for the $\mathrm{Ti}(\mathbf{A})$ and $\mathrm{Hf}$ (B) systems of Chart 1. With the dashed line are indicated the three classes (I, II, III) discussed in the text.

Here we remind that, contrarily to the $\mathrm{Zr}$ systems of Chart 1 , not all the $\mathrm{Ti}$ and $\mathrm{Hf}$ systems correspond to experimentally active catalysts. Apart from the nice correlation found for $\mathrm{Ti}$ and $\mathrm{Hf}$ (see the $\mathrm{R}^{2}$ square value reported in Figure $6 \mathbf{A}$ and $\mathbf{B}$ ), we would like to highlight the following points:

1) for each group 4 metal the points $\% V_{\mathrm{Bur}} v s \Delta G_{\mathrm{DFT}}$ are described reasonably well by a linear regression equation;

2) for each ligand there is a clear $\Delta G_{\mathrm{DFT}}$ trend being $\mathrm{Zr}<\mathrm{Hf}<$ $\mathrm{Ti}$; 
3) for each $\% V_{\mathrm{Bur}}$ value the same $\Delta G_{\mathrm{DFT}}$ trend $\mathrm{Zr}<\mathrm{Hf}<\mathrm{Ti}$ is found;

4) increase of the $\% V_{\mathrm{Bur}}$ over a certain value leads to the preference of a direct transfer $\left(\mathrm{BHT}_{\mathrm{B}}\right)$, with respect to the metalmediated $\mathrm{H}$ transfer $\left(\mathrm{BHT}_{\mathrm{A}}\right)$, although experimentally alternative chain transfers (e.g. BHE or $\beta$-methyl elimination) become predominant.

The Ti and Hf systems can be collected in three classes similarly to the $\mathrm{Zr}$ ones. However, we note that changing the metal from $\mathrm{Zr}$ to Ti results in a shift of several systems from class I to class II and from class II to class III, compare Figure 6A with Figure 5. The systems remaining in class $\mathbf{I}$ are the nonfluorinated octahedral bis(phenoxy-imine) systems 21 and 22. CGCs, octahedral and metallocenes systems without "suitable" modification or "proper" ligand belong to the class II, whereas the remaining systems are migrated to the class III, see Table S2. These results highlight the predominant role played by the metal. Ligand design by suitable substitution ${ }^{20,21}$ has been optimized for zirconocenes and any automatic extension to titanocenes should be avoided. Furthermore, the compact structure of octahedral Ti-system makes the chemical variation of both $\mathrm{R}^{1}$ and ortho-fluoro substitution much more effective. The intercept values of the three plots (59.6 for $\mathrm{Zr}$, see Figure 5, 58.4, 56.3 for Hf and Ti, see Figures $6 \mathbf{B}$ and A, respectively) confirm that less steric hindrance is requested for $\mathrm{Ti}$, and to some extent for $\mathrm{Hf}$, to reach larger $\Delta G_{\mathrm{DFT}}$, and thus higher molecular mass, with respect to $\mathrm{Zr}^{48}$ The plot of the Hf based systems appears to be more similar to the plot of the $\mathrm{Zr}$ systems, although both sterics and electronics concur into higher molecular mass (see Table S2). This is consistent with the experimental finding that for many classes of group 4 metallocene $^{4,20}$ and non-metallocene ${ }^{49}$ Hf-based propene polymerization catalysts yield polymers with higher average molecular weights than the $\mathrm{Zr}$-based homologues.

We stress once again that the reported $\Delta G_{\mathrm{DFT}}$ data are the $u p$ per limit values for the molecular mass prediction. This does not reflect immediately the experimental molecular mass, being suitable only if the chain transfer to the monomer is the prevailingly chain transfer mechanism.

As a final step, we derived a set of $\Delta G_{\text {Exp }}$ in order to perform a comparison with experimental results. The $\Delta G_{\operatorname{Exp}}$ measure the experimental free energy difference between the termination versus the propagation barriers promoted by catalytic systems of Chart 1 , where experimental molecular mass have been reported (see Table S3 of Supporting Information for further details). In Figure 7 we report two set of data. On the right part (red) we plot the $\Delta G_{\text {calc }} v s . \Delta G_{\text {Exp }}$ (where we used $\Delta G_{\text {calc }}$ because we included also prediction on BHE for system 13). The good correlation $\left(\mathrm{R}^{2}\right.$ square 0.94$)$ indicates that the quality of our theoretical approach is well spanned over the Group 4 metal catalysts. On the left part (black) we plot the $\% V_{\text {Bur }}$ versus $\Delta G_{\text {Exp }}\left(\right.$ or $\ln \left(M_{\mathrm{n}}\right)$, where the $M_{\mathrm{n}}$ are expressed in Da). We selected the $\% V_{\text {Bur }}$ of $\mathrm{Zr}$ systems because of the larger number of experimental data. Obviously, we did not included in the plot systems $\mathbf{1 4}$ and $\mathbf{1 5}$ because they belong to class III. Again, we found a remarkably good correlation $\left(\mathrm{R}^{2}\right.$ square 0.84 ) between the $\% V_{\mathrm{Bur}}$ of $\mathrm{Zr}$ neutral precursors and the $\Delta G_{\text {Exp }}$, see Figure 7 left, confirming the capability of the buried volume descriptor to rationalize the molecular mass capability of group 4 polymerization catalysts, independently from the specific coordination geometry and ligand scaffold.

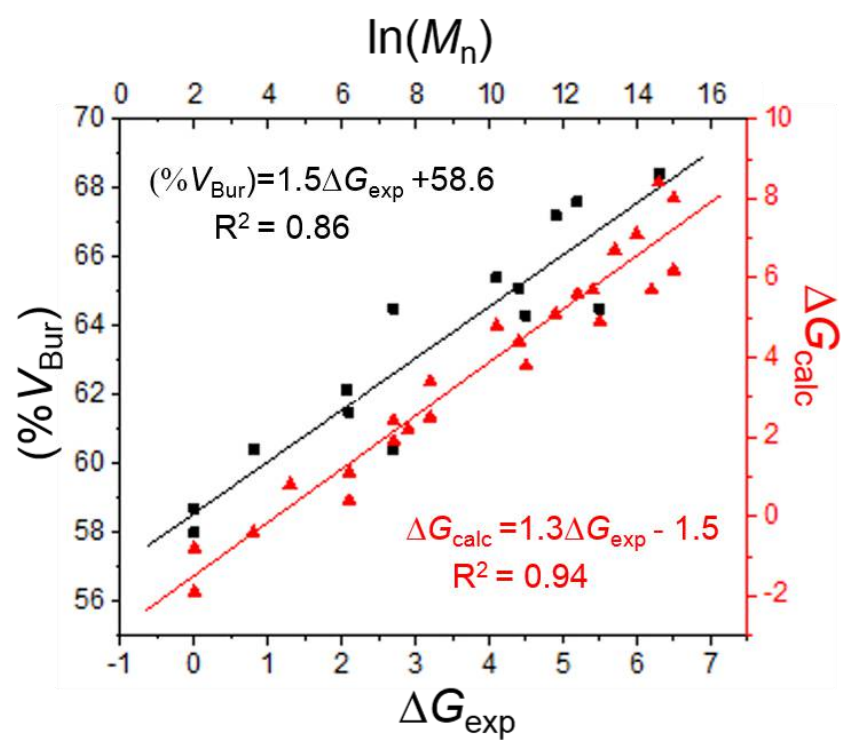

Figure 7. Plot of ( $\% V_{\text {Bur }}$ ) versus $\Delta G_{\text {exp }}$ (or $\ln \left(M_{\mathrm{n}}\right)$ expressed in Da) for the Zr systems of Chart 1 (left) and $\Delta G_{\text {calc }}$ versus $\Delta G_{\text {exp }}$ (right).

The "master curves" reported for $\mathrm{Zr}$ (see Figure 5), Ti and Hf (see Figure 6A and 6B) are a versatile tool not only to rationalize the properties of existing catalysts but also to operate a primary and secondary screening in combinations with highthroughput screening technologies for the development of new class of catalysts. ${ }^{48 \mathrm{~b}}$

\section{Conclusions}

In this paper we used the $\% V_{\text {Bur }}$ molecular descriptor to quantify and classify the steric properties of neutral precursor of Group 4 catalysts, with the final goal to correlate within a unique model the molecular mass capability of catalysts differing for geometry of coordination and structure of the ligand scaffold. The combined use of the $\% V_{\text {Bur }}$ and the steric maps allowed a nice rationalization of the guidelines reported in the literature. A linear correlation between the $\% V_{\text {Bur }}$ of the neutral precursors and the DFT calculated $\Delta G$ of propagation $v s$. chain transfer to the monomer is showed for all Group 4 metals.

The reported correlation allows to group, for the first time, the catalytic precursors into three classes (class I, II and III) producing polypropylenes with low molecular mass, increased molecular mass and intermediate/low molecular mass strictly depending of the experimental conditions, respectively. As consequence, the relationship between precursor structure/polypropylene properties can be extended also to the molecular mass in analogy with the symmetry rules concerning the enantioselectivity mechanism for propene polymerization catalysis. $^{7,8}$

From a methodological point of view, the "master curves" derived for $\mathrm{Ti}, \mathrm{Zr}$ and $\mathrm{Hf}$ systems promote our $\% V_{\mathrm{Bur}}$ as a suitable tool for a large screening of new olefin polymerization catalysts based on Group 4 metals, in particular for QSAR investigations.

As a concluding remark, we would like to insert our results in a more perspective view. In fact, from our analysis it appears that the extraordinary work performed since 90' on metallocene catalysts reached the highest level for zirconocenes and that there is not enough space to further improve the ratio between insertion and chain transfer to the 
monomer, at least for metallocenes. More intriguing possibilities appear for Ti-systems by using ligand scaffold different from ansa-metallocenes. ${ }^{48 a}$ A large space is emerging also for Hf systems as soon as the activity performances are optimized and new ligand frameworks are explored. ${ }^{48 b, 49}$ In conclusion, these results show that there is still space to tune Group 4 catalysts toward the synthesis of high molecular mass polymers.

\section{ASSOCIATED CONTENT}

Energies and free energies (B3LYP/TZVP and B3LYP/D3TZVP/PCM/ levels) and $\% V_{\text {Bur }}$ values of all the species considered (Table S1, Table S2). Comparison with experimental data (Table S3), Figure S1 discussed in the text and complete reference 28 . This material is available free of charge via the Internet at http://pubs.acs.org.

\section{AUTHOR INFORMATION}

\section{Corresponding Author}

*E-mail for G.T.: talarico@ unina.it, luigi.cavallo@kaust.edu.sa

\section{Author Contributions}

The manuscript was written through contributions of all authors.

\section{ACKNOWLEDGMENT}

G.T. thanks the Kaust Catalysis Center of King Abdullah University of Science and Technology, Saudi Arabia for the visiting contract KAUST-2015-C0546.

\section{REFERENCES}

(1) Gladysz, J. A. Chem. Rev. 2000, 100, full issue

(2) Ewen, J. A. J. Am. Chem. Soc. 1984, 106, 6355-6364.

(3) Kaminsky, W.; Külper, K.; Brintzinger, H. H.; Wild, F. R. W. P. Angew. Chem. Int. Ed. 1985, 24, 507-508.

(4) (a) Resconi, L.; Cavallo, L.; Fait, A.; Piemontesi, F. Chem. Rev. 2000, 100, 1253-1345.(b) Rappé, A. K.; Skiff, W. M.; Casewit, C. J. Chem. Rev. 2000, 100, 1435-1456.

(5) (a) 1.Margl, P.; Lohrenz, J. C. W.; Ziegler, T.; Blöchl, P. E. J. Am. Chem. Soc. 1996, 118, 4434. (b) Woo, T. K.; Margl, P. M.; Blöchl, P. E.; Ziegler, T. J. Am. Chem. Soc. 1996, 118, 13021.

(6) Talarico, G.; Budzelaar, P. H. M. J. Am. Chem. Soc. 2006, 128, 4524-4525.

(7) Farina, M. Macromol. Symp. 1995, 89, 489-498.

(8) (a) Ewen, J. A. J. Mol. Cat. A: Chem. 1998, 128, 103-109. (b) Ewen, J. A.; Elder, M. J.; Jones, R. L.; Haspeslagh, L.; Atwood, J. L.; Bott, S. G.; Robinson, K. Makromol. Chem., Macromol. Symp. 1991, 48-49, 253-295.

(9) (a) Corradini, P.; Guerra, G.; Cavallo, L. Acc. Chem. Res. 2004 37, 231-241. (b) Cavallo, L.; Guerra, G.; Vacatello, M.; Corradini, P. Macromolecules 1991, 24, 1784-1790. (c) Guerra, G.; Cavallo, L.; Moscardi, G.; Vacatello, M.; Corradini, P. Macromolecules 1996, 29, 4834-4845. (d) Milano, G.; Cavallo, L.; Guerra, G. J. Am. Chem. Soc. 2002, 124, 13368-13369.

(10) (a) Guerra, G.; Longo, P.; Cavallo, L.; Corradini, P.; Resconi, L. J. Am. Chem. Soc. 1997, 119, 4394-4403. (b) Toto, M.; Cavallo, L.; Corradini, P.; Moscardi, G.; Resconi, L.; Guerra, G. Macromolecules 1998, 31, 3431-3438.

(11) (a) Cavallo, L.; Guerra, G. Macromolecules 1996, 29, 27292737. (b) Talarico, G.; Budzelaar, P. H. M. Organometallics 2008, 27, 4098-4107.

(12) Resconi, L.; Piemontesi, F.; Franciscono, G.; Abis, L.; Fiorani, T. J. Am. Chem. Soc. 1992, 114, 1025-1032.

(13) Resconi, L.; Camurati, I.; Sudmeijer, O. Topics in Catalysis 1999, 7, 145-163.

(14) Caporaso, L.; De Rosa, C.; Talarico, G. J. Polym. Sci. Pol. Chem. 2010, 48, 699-708.
(15) Stevens, J.C.; Timmers, F.J.; Wilson, D.R.; Schmidt, G.F.; Nickias, P.N.; Rosen, R.K.; Knight, G.W.; Lai, S.-Y. Eur. Patent Appl. EP0416815, 1991.

(16) Canich, J.M.; Hlatky, G.; Turner, G.; Howard, W. Int. Patent Appl. WO/1992/000333, 1992.

(17) (a) van Leusen, D.; Beetstra, D. J.; Hessen, B.; Teuben, J. H. Organometallics 2000, 19, 4084-4089. (b) Sinnema, P.-J.; Hessen, B.; Teuben, J. H. Macromol. Rapid Commun. 2000, 21, 562-566.

(18) (a) Stevens, J. C. Stud. Surf. Sci. Catal. 1994, 89, 277-284. (b) Stevens, J. C. Stud. Surf. Sci. Catal. 1996, 101, 11-20; (c) McKnight, A. L.; Masood, M. A.; Waymouth, R. M.; Strauss, D. A. Organometallics 1997, 16, 2879-2885.

(19) Dang, V. A.; Yu, L.-C.; Balboni, D.; Dall'Occo, T.; Resconi, L.; Mercandelli, P.; Moret, M.; Sironi, A. Organometallics 1999, 18, 3781-3791.

(20) Spaleck, W.; Antberg, M.; Rohrmann, J.; Winter, A.; Bachmann, B.; Kiprof, P.; Behm, J.; Herrmann, W. A. Angew. Chem. Int. Ed. Engl. 1992, 31, 1347-1350.

(21) Stehling, U.; Diebold, J.; Kirsten, R.; Röll, W.; Brintzinger, H. H.; Jüngling, S.; Mülhaupt, R.; Langhauser, F. Organometallics 1994, 13, 964-970.

(22) Karttunen, V. A.; Linnolahti, M.; Pakkanen, T. A.; Severn, J. R.; Kokko, E.; Maaranen, J.; Pitkänen, P.; Pakkanen, A. J. Organomet. Chem. 2008, 693, 3915-3922.

(23) (a) Tshuva, E. Y.; Goldberg, I.; Kol, M. J. Am. Chem. Soc. 2000, 122, 10706-10707; (b) for a recent review on post-metallocene see Baier, M. C.; Zuideveld, M. A.; Mecking, S. Angew. Chem. Int. Ed. 2014, 53, 9722-9744.

(24) Busico, V.; Cipullo, R.; Pellecchia, R.; Ronca, S.; Roviello, G.; Talarico, G. Proc. Natl. Acad. Sci. U. S. A. 2006, 103, 1532115326.

(25) (a) Makio, H.; Terao, H.; Iwashita, A.; Fujita, T. Chem. Rev. 2011, 111, 2363-2449. (b) Domski, G. J.; Rose, J. M.; Coates, G. W.; Bolig, A. D.; Brookhart, M. Prog. Polvm. Sci. 2007, 32, 30-92.

(26) (a) Hillier, A. C.; Sommer, W. J.; Yong, B. S.; Petersen, J. L.; Cavallo, L.; Nolan, S. P. Organometallics 2003, 22, 4322-4326. (b) Dorta, R.; Stevens, E. D.; Scott, N. M.; Costabile, C.; Cavallo, L.; Hoff, C. D.; Nolan, S. P. J. Am. Chem. Soc. 2005, 127, 2485-2495. (c) Cavallo, L.; Correa, A.; Costabile, C.; Jacobsen, H. J. Organomet. Chem. 2005, 690, 5407-5413. (d) Poater, A.; Ragone, F.; Giudice, S.; Costabile, C.; Dorta, R.; Nolan, S. P.; Cavallo, L. Organometallics 2008, 27, 2679-2681. (e) Ragone, F.; Poater, A.; Cavallo, L. J. Am. Chem. Soc. 2010, 132, 4249-4258. (f) Wu, L. L.; Falivene, L.; Drinkel, E.; Grant, S.; Linden, A.; Cavallo, L.; Dorta, R. Angew. Chem. Int. Ed. 2012, 51, 2870-2873.

(27) (a) Poater, A.; Cavallo, L. Dalton Trans. 2009, 8878-8883. (b) Wucher, P.; Caporaso, L.; Roesle, P.; Ragone, F.; Cavallo, L.; Mecking, S.; Göttker-Schnetmann, I. Proc. Natl. Acad. Sci. USA 2011, 108, 8955-8959. (c) Poater, A.; Ragone, F.; Mariz, R.; Dorta, R.; Cavallo, L. Chem. Eur. J. 2010, 16, 14348-14353. (d) Ota, Y.; Ito, S.; Kuroda, J.; Okumura, Y.; Nozaki, K. J. Am. Chem. Soc. 2014, 136, 11898-11901.

(28) Reference Gaussian D01.

(29) (a) Becke, A. Phys. Rev. A 1988, 38, 3098-3100. (b) Perdew, J. P. Phvs. Rev. B 1986, 33, 8822-8824. (c) Perdew, J. P. Phys. Rev. B 1986, 34, 7406-7406.

(30) Schäfer, A.; Horn, H.; Ahlrichs, R. J. Chem. Phvs. 1992, 97, 2571-2577.

(31) (a) Dolg, M.; Stoll, H.; Preuss, H. Theor. Chim. Acta 1993, 85 , 441-450. (b) Bergner, A.; Dolg, M.; Kuechle, W.; Stoll, H.; Preuss, H. Mol. Phys. 1993, 80, 1431-1441.

(32) (a) Weigend, F.; Furche, F.; Ahlrichs, R. J. Chem. Phys. 2003 , 119, 12753-12762. (b) Schäfer, A.; Huber, C.; Ahlrichs, R. J. Chem. Phys. 1994, 100, 5829-5835.

(33) Barone, V.; Cossi, M. J. Phys. Chem. A 1998, 102, 19952001

(34) (a) Grimme, S.; Antony, J.; Ehrlich, S.; Krieg, H. J. Chem. Phys. 2010, 132, 154104/1-154104/19. (b) Grimme, S., J. Comput. Chem. 2004, 25, 1463-1473.

(35) Poater, A.; Cosenza, B.; Correa, A.; Giudice, S.; Ragone, F.; Scarano, V.; Cavallo, L. Eur. J. Inorg. Chem. 2009, 1759-1766. 
(36) SambVca 2.0, development version.

(37) Bondi, A. J. Phvs. Chem. 1964, 68, 441-451.

(38) (a) Ewen, J. A.; Jones, R. L.; Razavi, A.; Ferrara, J. D. J. Am. Chem. Soc. 1988, 110, 6255-6256. (b) Razavi, A.; Ferrara, J. J. Organomet. Chem. 1992, 435, 299-310.

(39) (a) Harney, M. B.; Keaton, R. J.; Fettinger, J. C.; Sita, L. R. J. Am. Chem. Soc. 2006, 128, 3420-3432. (b) Busico, V.; Carbonniere, P.; Cipullo, R.; Pellecchia, R.; Severn, J. R.; Talarico, G. Macromol. Rapid Commun. 2007, 28, 1128-1134.

(40) Hustad, P. D.; Tian, J.; Coates, G. W. J. Am. Chem. Soc. 2002 124, 3614-3621.

(41) Mitani, M.; Nakano, T.; Fujita, T. Chem.Eur.J. 2003, 9, 2396-2403.

(42) Talarico, G.; Busico, V.; Cavallo, L. J. Am. Chem. Soc. 2003, $125,7172-7173$.

(43) Talarico, G.; Busico, V.; Cavallo, L. Organometallics 2004, 23, 5989-5993.

(44) Kock, W.; Holthausen, M. C. A Chemist's Guide to Density Functional Theory, Wiley-VCH: Weinheim, 2000; (b) Talarico, G.; Blok, A. N. J.; Woo, T. K.; Cavallo, L. Organometallics 2002, 21, 4939-4949.

(45) On the basis of the reported results we are currently working for further modification of the SambVca program to take into account also electronic effects.

(46) From the Boltzman distribution value below $2 \mathrm{kcal} / \mathrm{mol}$ correspond to the $M_{\mathrm{n}}$ below $1 \mathrm{kDa}$ at $50{ }^{\circ} \mathrm{C}$.
(47) From the Figure 5 appears difficult going over system 12 (e.g. $\Delta G$ value $>8.5 \mathrm{kcal} / \mathrm{mol}$ ) without constrain the metal site in such a way that BHE and $\beta$-methyl elimination became favourable pathways for termination. It is worth to recall that system $\mathbf{1 2}$ is the zirconocene used for industrial application, see e.g. Brintzinger, H. H.; Fischer, D. Adv. Polvm. Sci. 2013, 258, 29-42; for zirconocene patent see Winter A, Antberg M, Spaleck W, Rohrmann J, Dolle V (1990) Patent EP $485,821 \mathrm{~B} 1$.

(48) From Figure 6 A $\Delta G$ values $>8.5 \mathrm{kcal} / \mathrm{mol}$ appear more accessible for $\mathrm{Ti}$ (see system 26) without using so bulky metallocene framework (see Table S1). From Figure $6 \mathrm{~B} \Delta G$ values $>8.5 \mathrm{kcal} / \mathrm{mol}$ can be reached also by Hf systems. Polypropylenes with very high molecular mass promoted by (a) new octahedral Ti-systems and (b) pyridylamido-Hf systems have been reported: for (a) see Press, K.; Cohen, A.; Goldberg, I.; Venditto, V.; Mazzeo, M.; Kol, M. Angew. Chem. Int. Ed. 2011, 50, 3529-3532; for (b) see Boussie, T. R.; Diamond, G. M.; Goh, C.; Hall, K. A.; LaPointe, A. M.; Leclerc, M. K.; Murphy, V.; Shoemaker, J. A. W.; Turner, H.; Rosen, R. K.; Stevens, J. C.; Alfano, F.; Busico, V.; Cipullo, R.; Talarico, G. Angew. Chem. Int. Ed. 2006, 45, 3278-3283. However, in both cases the nature of active species is a matter of debate.

(49) Cipullo, R.; Busico, V.; Fraldi, N.; Pellecchia, R.; Talarico, G. Macromolecules 2009, 42, 3869-3872. 
2

3

4

7

Insert Table of Contents artwork here

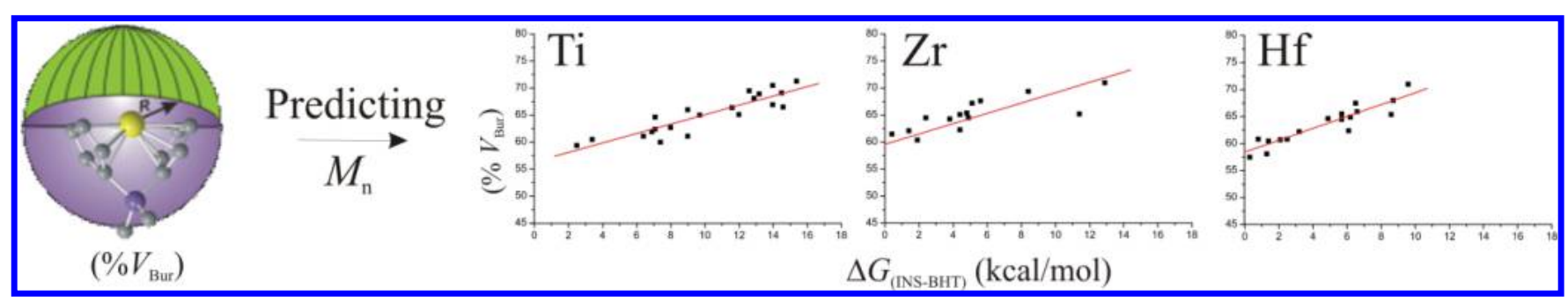

